\title{
Analysis on the Impact of Government-Enterprise Cooperation on Technological Innovation and Its Economic Consequences
}

\section{--Based on Empirical Cases of GEM-Listed Companies}

\author{
Xiaomei Chen ${ }^{1}$,Yun Xia ${ }^{1}$, Junda Yang ${ }^{1}$ \\ ${ }^{1}$ Finance Department of International Business School,Jinan University, China \\ Correspondence: Yun Xia, Finance Department of International Business School, Jinan University, Qianshan Road 206\#, \\ Zhuhai City, Guangdong Province, Post NO. 519070, China.
}

\author{
Received: October 15, 2018 \\ Accepted: October 29, 2018 \\ Online Published: November 8, 2018 \\ doi:10.11114/bms.v4i4.3755 \\ URL: https://doi.org/10.11114/bms.v4i4.3755
}

\begin{abstract}
Based on the GEM listed companies in 2009-2016, the authors discuss the impact of government-enterprise cooperation on enterprise technology innovation and its actual economic consequences from the two dimensions of R\&D investment and corporate performance. The empirical results of this paper are as follows: the government-enterprise cooperation model does not promote enterprises to invest more funds for technological innovation, but it has a positive effect on corporate performance. The conclusion of this paper provides a new perspective and empirical evidence for us to understand the nature of government-enterprise cooperation and its impact on the entire economic market. It has strong theoretical and practical significance.
\end{abstract}

Keywords: government-enterprise cooperation, technology innovation, corporate performance

\section{Introduction}

Due to the rapid changes in innovation technology, the quasi-publicity of industrial common technologies, and the enrichment of supply chain choices, the boundaries of the modern enterprises have become increasingly blurred. Enterprises and enterprises, universities and enterprises, governments and enterprises all have more Opportunity to cooperate. In recent years, with the support of national policies, the cooperation between Chinese government and enterprises tend to be more in-depth and extensive. At the 2016 National Science and Technology Innovation Conference, General Secretary Xi Jinping's proposal to support the National Technology Innovation Center based on enterprise construction once again focused everyone's attention on government-enterprise cooperation and technological innovation. At present, China is at the critical stage of the transformation and upgrading of the manufacturing industry. To realize the transformation from a manufacturing power to a manufacturing power at an early date, how the government can better guide the innovation strategic alliance and optimize the cooperation mode to enhance the technological innovation capability of Chinese enterprises has become an urgent problem for the country. Therefore, theoretically exploring the survival status of government-enterprise cooperation enterprises can not only provide theoretical guidance for Chinese enterprises to fully understand their own situation, recognize their own needs and development direction, but also help us to correctly evaluate the advantages and disadvantages of such cooperation. And recognize the government's positioning in the economic market, and then provide useful reference for the country in formulating corresponding economic policies, tax policies, environmental policies, laws and regulations. Why is this problem important?

At the macro level, the central government, which represents the highest interests of China as a whole, encourages and guides enterprises to carry out technological innovation through policy orientation and establishment of technological innovation centers, which has enabled many enterprises to cooperate with the government; at the micro level, Can the expected model of government-enterprise cooperation really promote technological innovation in enterprises? At the same time, what is the state of business and profitability of government-enterprise cooperation? Since the cooperation between government and enterprises and the development of government-enterprise alliances are not long, scholars' research on such partnerships focuses on building models, analyzing concept definitions, and organizational differences while there is not much research on the innovation ability and competitiveness of government-enterprise cooperative enterprises with Chinese characteristics. There is also great controversy among existing research scholars. 
Regarding the effect of government-enterprise cooperation, one view is that cooperation between the government and enterprises has a positive effect on the R\&D and innovation of enterprises. Zhu Pingfang et al. (2003) studied the impact of the introduction of science and technology incentives on technological innovation within enterprises from the perspective of the government. Liu Xiaoyuan (2013) starts from the dual perspectives of technology innovation resource allocation and innovation output, and empirically studies local governments to promote technological innovation of startup enterprises through subsidies and income tax benefits. Wang Yebin (2013) analyzes the research on government investment and financial credit, and finds that the influence of government behavior on enterprise technology innovation is significant in the financial aspect. In 2012, ZanderI analyzed from two regional and international macro levels, and believed that the role of the government in the alliance is not only domestically effective. In promoting the process of internationalization and innovation, it also attracts foreign investment by optimizing the domestic innovation environment. The effect of entering the market. Long Jing et al. (2012) believe that government agencies have their own unique power resources to actively play on SMEs, enhance the relationship between government and enterprises, and have a positive impact on the technological innovation of SMEs. From the study of the role of government in innovation, LucaLMD (2007) believes that the government's role in innovation is mainly reflected in policy support, policy guidance and policy support. Guo Jing, Chen Yongqi and other scholars (2013) study that the government acts on enterprises through policy orientation. Compared with market orientation, enterprise technology innovation performance is more influenced by market orientation. When policy orientation and market orientation are balanced on enterprises, The positive impact of innovation is most significant . Sun Demei et al. (2014) concluded that government behavior and financial development play a positive role in innovation performance, while the research on the role of financial development needs to be sustained and postponed, and it needs lag data to show its role. When the premise adjustment is changed to a dynamic environment, the positive effect of government behavior on innovation performance is as lagging as financial development. Xiao Liping (2016) quantifies the behavior of government-enterprise contact into data through the target design function, and constructs a decision-making model that reflects the technological innovation of the enterprise. When the local government intervention increases, it is positively promoting the innovation between schools and enterprises. Output. Zhou Qiongqiong and Hua Qingsong (2015) found through research that the government played a role in the allocation of science and technology resources, which indirectly made the company's technological innovation capability more prominent and achieved better results.

However, another view is that the government is counterproductive or incosistent to the company's innovative behavior. Yang Ruoyu (2016) obtained empirical analysis that local protection has a negative effect on regional innovation performance. Bai Chongen et al. (2015) found that if there is local protection in the region, it can be inferred that the local government's tax rate policy is generally high, and the regional enterprises are also highly nationalized. There are also many scholars who study the impact of government action on enterprises from the perspective of policy guidance and financial support. Fan Qi et al. (2011) empirically found that in China, enterprise independent innovation and government innovation R\&D investment policies have complementary relationships, but when the market competition level exceeds the critical value of the inverted U-shaped top, the promotion effect of government innovation R\&D investment policy sharply declines. Gu Yuanyuan and Shen Kunrong (2012) believe that the relationship between the government and the enterprise is related to the social environment. When the environment of the enterprise gets worse, the government intervenes in the enterprise tend to be more, resulting in the lower the independent control of the enterprise. Xiao Wen (2014) found that the government's long-term goal in the market conflicts with the pursuit of short-term goals, and that there is a mismatch between corporate sales and R\&D management, resulting in a negative correlation between government behavior and corporate technology innovation efficiency. Luo Mingxin (2013) used data analysis of China's GEM listed companies and found that political connections have a negative effect on technological innovation performance through the intermediary role of R\&D investment. Zhou Qiongqiong, Yuan Lijing (2017) found that there is a "U-shaped" relationship between environmental regulation and enterprise technology innovation. Appropriate use of government subsidy behavior in the negative stage of the "U-shaped" process can promote the development of technological innovation in enterprises.

Based on the existing research, this paper takes the companies listed on China Growth Enterprise Market (GEM), from the two dimensions of the status quo and development, empirically tests the series of influences of the government's participation in the technological innovation of the alliance and its economic consequences. It not only evaluates the current and sustainable development of the formation of government-enterprise alliances from the micro level, but also provides theoretical and practical basis for the formulation and reform of relevant policies, which has important implications for understanding the role of government and enterprise cooperation in China's economic development, improving national innovation system and formulating industrial policies. 


\section{Theoretical Analysis and Research Hypotheses}

\subsection{Definition of the Concept of Government-Enterprise Cooperation}

The government-enterprise cooperation discussed in this paper is defined as the government-enterprise relationship in which the government and enterprises have publicly issued cooperation statements in public platforms such as newspapers, websites, press conferences, and media. The cooperation between government and enterprises here can be equated with the concept of government-enterprise alliance, that is, the cooperation mode between government and enterprises for resource sharing, information exchange and risk sharing due to a certain project or common goal. In addition, the government-enterprise cooperation referred to in this article does not necessarily refer to state-owned enterprises, nor does it only refer to enterprises that accept government subsidies, and it must be based on the public release statement, which is also a prerequisite for the empirical data collection.

\subsection{Proposal of Research Hypotheses}

In modern times, American management scientist R. Nigel and DEC president J. Hopland both proposed the concept of "strategic alliance" for the first time in the history of management. With the development of China's reform and openingup, driven by countries with rapid economic development such as Japan and the United States, enterprise-enterprise cooperation model, industry-university-research cooperation model, and government-enterprise cooperation model also have begun to emerge in our country. In 2008, the Chinese government issued the "Guiding Opinions on Promoting the Construction of Strategic Alliances for Industrial Technology Innovation", which further promoted the cooperation between the government and enterprises. By June 2012, when the Office of the Ministry of Science and Technology issued the "Economic Technology Innovation Strategic Alliance Evaluation Work Plan, the cooperation between government and enterprises has become one of the mainstreams of the cooperation model. "Notice of the Ministry of Science and Technology on Printing and Distributing the Guidelines for the Construction of National Technology Innovation Centers" promulgated in 2017 clearly clarifies that the direction of "supporting the construction of national technology innovation centers based on enterprises" proposed by General Secretary Xi Jinping needs to be fully implemented and will establish a technology innovation center to play a role. Based on the above-mentioned environment created by the Chinese government, the government-enterprise cooperation has a very reasonable formation motivation and motivation support, and it can also obtain the government's allocated innovation funds. At the same time, government-enterprise cooperation is also a form of political alliance, which enables members to share resources and improve the ability of innovative resources to use (Xiangjie Zheng,2014). Based on the internal government and business managers, government officials have won higher promotion opportunities for themselves. To achieve their political goals and social tasks, they have cooperated with large-scale and high-quality enterprises to fulfill their political demands (Yuanyuan Gu \& Kunrong Shen,2012). And companies also want to get government-specific public and administrative resources. The alliance between the government and enterprises not only involves the cooperation needs in the macro environment, but also the needs of deep levels and their own interests. Under such a complex multi-demand model, what impact will it have on the current state of the enterprise and sustainable development? The author hopes to comprehensively evaluate the enterprise by analyzing the technical innovation of the government-enterprise cooperation enterprise and the current situation of the business operation. Technological innovation represents the possibility that enterprises will grasp more core competitiveness in the future, and is an indicator for enterprise upgrading and sustainable development. The current state of business management is the most intuitive description of the current state of the enterprise, and it is a possibility to evaluate whether the enterprise can carry out technological innovation. According to the research and analysis of most scholars (Bing Li, Yunqi Yue \& Ting Chen,2016), for technological innovation, we select the R\&D data of the enterprise for analysis, while for the current state of business, we choose the performance of the enterprise to measure. Therefore, this paper proposes the following assumptions:

Hypothesis 1-a: If the other things remain unchanged, government-enterprise cooperation is positively related to corporate R\&D investment (R\&D) under other conditions.

Hypothesis 1-b: If the other things remain unchanged, government-enterprise cooperation is negatively related to corporate R\&D investment (R\&D).

Hypothesis 2-a: If the other things remain unchanged, government-enterprise cooperation is positively related to corporate performance.

Hypothesis 2-b: If the other things remain unchanged, government-enterprise cooperation is negatively related to corporate performance. 


\section{Study Design}

\subsection{Data Sources and Sample Selection}

The GEM is a "second board market" in the Chinese stock market. Entrepreneurial companies, high-tech enterprises, small and medium-sized enterprises that have not yet entered the main board market have become the main enterprises of the GEM. In the past ten years, China's economy has developed rapidly and its forms of enterprises are diverse. The GEM market provides a high-quality competitive platform for small and medium-sized enterprises to finance and innovate technology. In October 2009, the China GEM was officially launched in the stock market, providing continuous, comprehensive and reliable empirical data for the research and discussion of economics on small and medium-sized enterprises and high-tech innovative enterprises. The author is also based on this point, and will explore the empirical data of government-enterprise cooperative enterprises as the research object.

The financial data required for the empirical sample of this paper was selected from the China Taian Database (CSMAR), the annual reports of various enterprises and the enterprise portal website. The time period was selected from the data of the GEM listed companies during 2009-2016. Since the definition of enterprise alliance needs special division, and there is no clear classification in the data, the author manually sorts, extracts, and sorts out the target data required by this article from the annual report of the enterprise. After eliminating the missing and suspicious data, a total of 6,774 observation samples were obtained in this paper.

\subsection{Model Specification and Variable Definition}

To test hypothesis 1-a, 1-b. We establish the following regression models, models (1)-(3). According to the relevant literatures of scholars such as Gu Yuanyuan, Shen Kunrong (2012), Chen Yu (2016), Xiao Liping (2016), this paper will focus on the R\&D investment data of government-enterprise cooperative enterprises (interpreted variables). It is measured by three joint indicators: $R \& D /$ total assets, $R \& D / 10,000$ yuan, and $\ln (R \& D+1)$. the explanatory variable is whether it is a government-enterprise cooperative enterprise, and the enterprise belonging to the government-enterprise alliance cooperation category is recorded as " 1 ", and vice versa as " 0 ". In the selection of control variables, referring to the relevant researches in the previous literature, we select the six comprehensive indicators of enterprise size, asset-liability ratio, gross profit margin, total return on assets, growth rate of operating income, and shareholding ratio of the largest shareholder.

$$
\begin{aligned}
& R d 1=\beta_{0}+\beta_{1} P t+\beta_{2} \text { RoA }+\beta_{3} \text { Grow }+\beta_{4} \text { Sm }+\beta_{5} \text { Size }+\beta_{6} \text { Firststock }+\beta_{7} \text { Lev }+\beta_{8} \text { Year }+\beta_{9} \text { Industry }+\varepsilon_{0} \\
& R d 2=\alpha_{0}+\alpha_{1} \text { Pt }+\alpha_{2} \text { RoA }+\alpha_{3} \text { Grow }+\alpha_{4} \text { Sm }+\alpha_{5} \text { Size }+\alpha_{6} \text { Firststock }+\alpha_{7} \text { Lev }+\alpha_{8} \text { Year }+\alpha_{9} \text { Industry }+\varepsilon_{1} \\
& R d 3=\gamma_{0}+\gamma_{1} \text { Pt }+\gamma_{2} \text { RoA }+\gamma_{3} \text { Grow }+\gamma_{4} \text { Sm }+\gamma_{5} \text { Size }+\gamma_{6} \text { Firststock }+\gamma_{7} \text { Lev }+\gamma_{8} \text { Year }+\gamma_{9} \text { Industry }+\varepsilon_{2}
\end{aligned}
$$

To test hypotheses 2-a, 2-b, we propose the following regression model, models (4)-(5). According to Deng Xinghua, Lin Zhouyi (2014), Zhang Rui (2014), Li Mengyang, Guo Chaoyang (2017) and other related literature, this paper will use revenue and Tobin $\mathrm{Q}$ to measure the performance of the company (the explanatory variable). These four indicators are also key statistics reflecting the business status of the company. The explanatory variable is still whether it is a government-enterprise cooperative enterprise. Enterprises belonging to the government-enterprise alliance cooperation category are recorded as " 1 ", and vice versa as " 0 ". In terms of control variables, referring to the relevant research in the previous literature, we select firm size, asset-liability ratio, firm life cycle, firm ' $\mathrm{s}$ cash flow, executive pay, proportion of the largest shareholder, ultimate holder, CEO duality, industry, year, these ten comprehensive indicators.

$$
\begin{aligned}
& \text { Re venue }=\varphi_{0}+\varphi_{1} P t+\varphi_{2} \text { Age }+\varphi_{3} \text { Cashflow }+\varphi_{4} \text { Pay }+\varphi_{5} \text { Size }+\varphi_{6} \text { Firststock } \\
& +\varphi_{7} \text { Lev }+\varphi_{8} \text { Year }+\varphi_{9} \text { Industry }+\varphi_{10} \text { Ulitimatecontrol }+\varepsilon_{4} \\
& \text { Tobins } Q=\mu_{0}+\mu_{1} P t+\mu_{2} \text { Age }+\mu_{3} \text { Cashflow }+\mu_{4} \text { Pay }+\mu_{5} \text { Size }+\mu_{6} \text { Firststock } \\
& +\mu_{7} \text { Lev }+\mu_{8} \text { Year }+\mu_{9} \text { Industry }+\mu_{10} \text { Ulitimatecontrol }+\varepsilon_{7}
\end{aligned}
$$


Table 1. Variables definition

\begin{tabular}{|c|c|c|c|}
\hline & Variable & Symbol & Definition \\
\hline \multirow{5}{*}{$\begin{array}{l}\text { Dependent } \\
\text { variable }\end{array}$} & \multirow{3}{*}{ R\&D input } & $R d 1$ & $R d 1=\mathrm{R} \& \mathrm{D}$ expenditures/total assets at year-end \\
\hline & & $R d 2$ & $R d 2=\mathrm{R} \& \mathrm{D}$ expenditures $/ 10000$ \\
\hline & & $R d 3$ & $R d 3=\ln (\mathrm{R} \& \mathrm{D}$ expenditures +1$)$ \\
\hline & \multirow{2}{*}{ Performance } & Revenue & $\begin{array}{c}\text { Revenue }=\text { main business income }+ \text { other business } \\
\text { income }\end{array}$ \\
\hline & & Tobins $Q$ & $\begin{array}{c}\text { Tobins } Q=\text { ( market value of ordinary shares at year- } \\
\text { end }+ \text { total liabilities at year-end ) / total assets at } \\
\text { vear-end }\end{array}$ \\
\hline $\begin{array}{l}\text { Explanatory } \\
\text { variable }\end{array}$ & $\begin{array}{l}\text { Whether it is a } \\
\text { government-enterprise } \\
\text { cooperative enterprise }\end{array}$ & $P t$ & $\begin{array}{l}\text { Dummy variable. If government cooperate with the } \\
\text { enterprise, the value is } 1 \text {; otherwise, the value is } 0\end{array}$ \\
\hline \multirow[t]{4}{*}{ control variable } & Return on assets & $R O A$ & $R O A=$ net profit $/$ average total assets \\
\hline & $\begin{array}{l}\text { Main business revenue } \\
\text { growth rate }\end{array}$ & Grow & $\begin{array}{c}\text { Grow }=\text { (main business income of this year - main } \\
\text { business income of last year) / main business } \\
\text { income of last year } * 100 \%\end{array}$ \\
\hline & Sales margin & $S m$ & $\begin{array}{c}S m=(\text { main business income }- \text { main business cost }) \\
/ \text { main business income } * 100 \%\end{array}$ \\
\hline & Firm size & Size & Size $=\ln ($ total assets at year-end $)$ \\
\hline
\end{tabular}

\begin{tabular}{ccc}
\hline $\begin{array}{c}\text { Proportion of the } \\
\text { largest shareholder }\end{array}$ & Firststock & $\begin{array}{c}\text { The propotion of the largest shareholder's } \\
\text { shareholding in the companies }\end{array}$ \\
\hline Asset-liability ratio & Yev & $\begin{array}{c}\text { Lev }=\text { total liabilities at year-end / total assets at year- } \\
\text { end *100\% }\end{array}$ \\
\hline Year effect & Industry & $\begin{array}{c}\text { We define seven dummy variables, for which the } \\
\text { benchmark year is } 2009\end{array}$ \\
Industry effect & $\begin{array}{c}\text { Dumb variables, according to the "Guidelines for } \\
\text { Listed Companies' Industry Classification", the listed } \\
\text { companies are divided into } 12 \text { industry categories } \\
\text { (excluding financial industries), and 11 industry } \\
\text { dummy variables are set. If the listed company is a } \\
\text { reference system, take } 1 ; \text { otherwise take } 0 .\end{array}$ \\
\hline Firm life cycle & Age & $\begin{array}{c}\text { The survival time of the firm from the beginning to } \\
\text { this year }\end{array}$ \\
\hline
\end{tabular}

\begin{tabular}{|c|c|c|}
\hline Firm cash flow & Cashflow & $\begin{array}{l}\text { Cashflow }=\text { operating income of this year - cash cost - } \\
\text { income tax }\end{array}$ \\
\hline Executive pay & Pay & $\begin{array}{c}\text { The compensation level of executives in the target } \\
\text { enterprise }\end{array}$ \\
\hline Ultimate holder & Ulitimatecontrol & $\begin{array}{c}\text { dummy variable equal to } 1 \text { for a state-owned } \\
\text { enterprise and } 0 \text { otherwise }\end{array}$ \\
\hline CEO duality & Dual & $\begin{array}{c}\text { dummy variable equal to } 1 \text { for CEO duality and } 0 \\
\text { otherwise }\end{array}$ \\
\hline
\end{tabular}




\section{Empirical Result}

\subsection{Descriptive Statistical Analysis}

Table 2. Government-enterprise cooperative enterprise

\begin{tabular}{|c|c|c|c|c|c|}
\hline \multirow[t]{2}{*}{$\mathrm{Pt}$} & \multicolumn{2}{|c|}{0} & \multicolumn{2}{|l|}{1} & \multirow[b]{2}{*}{ Total } \\
\hline & number & percentage & number & percentage & \\
\hline \multicolumn{6}{|l|}{ Year } \\
\hline 2009 & 19 & $76.00 \%$ & 6 & $24.00 \%$ & 25 \\
\hline 2010 & 70 & $72.16 \%$ & 27 & $27.84 \%$ & 97 \\
\hline 2011 & 131 & $74.43 \%$ & 45 & $25.57 \%$ & 176 \\
\hline 2012 & 166 & $74.77 \%$ & 56 & $25.23 \%$ & 222 \\
\hline 2013 & 166 & $74.77 \%$ & 56 & $25.23 \%$ & 222 \\
\hline 2014 & 191 & $76.71 \%$ & 58 & $23.29 \%$ & 249 \\
\hline 2015 & 217 & $77.78 \%$ & 62 & $22.22 \%$ & 279 \\
\hline 2016 & 225 & $77.85 \%$ & 64 & $22.15 \%$ & 289 \\
\hline
\end{tabular}

According to Table 2, from the perspective of absolute number and relative number, we can find that in 2009-2016, more than $20 \%$ of enterprises have cooperated with the government $(\mathrm{Pt}=1)$. It shows that in recent years, government-enterprise cooperation has been widely applied in China.

Table 3. Descriptive statistics

\begin{tabular}{ccccccc}
\hline Variable & $\mathrm{N}$ & Min & Median & Max & Mean & SD \\
\hline$R d 1$ & 6774 & 0 & 0.0333 & 0.393 & 0.0446 & 0.0395 \\
\hline$R d 2$ & 6774 & 0 & 2999 & 185956 & 5157 & 7570 \\
\hline$R d 3$ & 6774 & 0 & 17.22 & 21.34 & 17.19 & 1.712 \\
\hline Revenue & 6774 & $7.790 \mathrm{e}+07$ & $4.470 \mathrm{e}+08$ & $4.130 \mathrm{e}+10$ & $7.410 \mathrm{e}+08$ & $1.150 \mathrm{e}+09$ \\
\hline Sm & 6774 & -12.17 & 39.46 & 96.83 & 42.51 & 17.84 \\
\hline$R O A$ & 6774 & -46.84 & 6.452 & 37.25 & 6.637 & 5.900 \\
\hline TobinsQ & 6419 & 0.603 & 3.231 & 24.94 & 3.853 & 2.625 \\
\hline Pt & 6774 & 0 & 0 & 1 & 0.0552 & 0.228 \\
\hline Size & 6774 & 19.56 & 20.94 & 24.20 & 21.04 & 0.698 \\
\hline Lev & 6774 & 0.0110 & 0.198 & 0.843 & 0.232 & 0.150 \\
\hline Age & 6774 & 4 & 13 & 30 & 13.03 & 4.166 \\
\hline Firststock & 6774 & 0.0438 & 0.291 & 0.812 & 0.309 & 0.123 \\
\hline Grow & 6774 & -79.09 & 21.22 & 557.0 & 27.44 & 43.35 \\
\hline Cashflow & 6774 & -1.481 & 0.0410 & 1.030 & 0.0498 & 0.135 \\
\hline Pay & 6763 & 124000 & $1.278 \mathrm{e}+06$ & $9.595 \mathrm{e}+06$ & $1.473 \mathrm{e}+06$ & 978735 \\
\hline Ultimateconontrol & 6774 & 0 & 0 & 1 & 0.0309 & 0.173 \\
\hline Dual & 6749 & 0 & 0 & 1 & 0.451 & 0.498 \\
\hline
\end{tabular}

According to Table 3, it can be statistically concluded that the median of 0.033 of Rd1 (R\&D/total assets) is very close to the average of 0.0446 , while the standard deviation is 0.0395 . The median 17.22 of $\operatorname{Rd} 3(\operatorname{Ln}(R \& D+1))$ is very close to the average 17.19 , while the standard deviation is 1.712 . It shows that the dispersion of samples of $\mathrm{Rd} 1(\mathrm{R} \& \mathrm{D} /$ total assets) and $\operatorname{Rd} 3(\operatorname{Ln}(R \& D+1))$ is not high. Compared with $R d 1(R \& D / t o t a l$ assets) and $R d 3(\operatorname{Ln}(R \& D+1))$, the degree of dispersion of $\mathrm{Rd} 2(\mathrm{R} \& \mathrm{D} / 10000)$ is relatively high. From the data of size (firm size), the scale of enterprises in government-enterprise cooperation is not much different. Lev (asset-liability ratio) has a maximum value of 0.843 , a minimum of 0.0110 , and an average of 0.232 , indicating that most of the government-enterprise cooperation Lev (assetliability ratio) is below the median. The situation of Firststock (proportion of the largest shareholder) is like that of Lev 
(asset-liability ratio). Although the median of ROA (Return on assets) is close to the average, the span between minimum and maximum is relatively large, and the standard deviation also reaches 5.900, indicating that the Return on total assets of different government-enterprise cooperatives is not stable. The minimum value of Grow (main business revenue growth rate) reached 79.09 , indicating that the risk of R\&D investment is large, which is in line with the development of real enterprise R\&D investment. The differences between maximum value and minimum value of Sm (sales margin) and ROA (return on assets) are both large, and the data spans of them are both between positive and negative, indicating that the profit and gross profit of the government-enterprise cooperative enterprise also has a loss when it is profitable.

On the other hand, it can be statistically concluded that the minimum value of Revenue (operating income) is $7.790 \mathrm{e}+07$, and the maximum value is $4.130 \mathrm{e}+10$, indicating the disparity in income between enterprises in government-enterprise cooperation. The maximum value of TobinsQ (Tobin Q value) is 24.94 , the minimum value is 0.603 , and the standard deviation is 2.625 , indicating that most of the enterprises that cooperate with government are concentrated near the median TobinsQ. Age (firm life cycle) is mostly concentrated in the age of enterprises for more than ten years, during which China's economy develops rapidly and the government begins to increase business cooperation. From the data of Size (frim size), we can find that the scale of government-enterprise cooperative enterprises doesn't appear to be much different.

\subsection{Correlation Analysis}

Table 4. Correlation statistics of major variables

\begin{tabular}{|c|c|c|c|c|c|}
\hline \multirow[t]{2}{*}{ Variable } & $R d 1$ & $R d 2$ & $R d 3$ & Revenue & Tobins $Q$ \\
\hline & \multicolumn{3}{|c|}{ Hypothesis 1} & \multicolumn{2}{|c|}{ Hypothesis 2} \\
\hline$P t$ & $-0.078 * * *$ & -0.014 & $-0.078 * * *$ & $0.101 * * *$ & $-0.051 * * *$ \\
\hline$R O A$ & $0.291 * * *$ & $0.094 * * *$ & 0.017 & - & - \\
\hline$S m$ & $0.326^{* * *}$ & $0.049 * * *$ & $0.070 * * *$ & - & - \\
\hline Size & $-0.068 * * *$ & $0.538 * * *$ & $0.286^{* * *}$ & $0.593 * * *$ & $-0.152 * * *$ \\
\hline Lev & $-0.151 * * *$ & $0.194 * * *$ & $0.114 * * *$ & $0.350 * * *$ & $-0.086 * * *$ \\
\hline Age & - & - & - & $0.103 * * *$ & $0.100 * * *$ \\
\hline Firststock & $-0.144 * * *$ & $-0.106 * * *$ & $-0.138 * * *$ & -0.015 & $0.034 * * *$ \\
\hline Grow & $0.175 * * *$ & $0.141 * * *$ & $0.065 * * *$ & $0.201 * * *$ & $0.103 * * *$ \\
\hline Cashflow & - & - & - & -0.007 & $0.240 * * *$ \\
\hline Pay & - & - & - & $0.366^{* * *}$ & $0.057 * * *$ \\
\hline Ultimateconontrol & - & - & - & -0.013 & $0.032 * * *$ \\
\hline Dual & - & - & - & -0.018 & $0.029 * *$ \\
\hline
\end{tabular}

Note: * Statistical significance at the $10 \%$ level, ** Statistical significance at the $5 \%$ level *** Statistical significance at the $1 \%$ level

In Table 4, the correlation between the main variables and the control variables of Hypothesis 1 and 2 in this paper is analyzed. For hypothesis 1 , we can find that $\mathrm{Rd} 1, \mathrm{Rd} 3$ are both in a significant negative correlation with $\mathrm{Pt}$ (governmententerprise cooperation) at the $1 \%$ level while $\mathrm{Rd} 2$ and $\mathrm{Pt}$ (government-enterprise cooperation) are not significantly negatively correlated, and their relationship is not clear. For this item, we will continue to discuss their relevance in the following regression analysis. Compared with $\mathrm{Rd} 2$ and $\mathrm{Rd} 3$, the negative correlation between Rd1 and other control variables is more significant. It has a negative correlation with Size (firm size), Lev (asset-liability ratio) and Firststock (proportion of the largest shareholder). Moreover, Sm (sale margin) is positively correlated with $\mathrm{Rd} 2, \mathrm{Rd} 3$ and $\mathrm{Rd} 1$. The corresponding correlation coefficients are significant at the $1 \%$ level.

For Hypothesis 2, as shown in Table 4, Revenue (operating income), TobinsQ (Tobin Q value) are both in a significant negative correlation with Pt (government-enterprise cooperation) at the $1 \%$ level. Among the control variables, Size (enterprise size), Age (firm life cycle), Lev (a asset-liability ratio), Pay (executive pay) are all significantly related to Revenue (operating income) at the level of $1 \%$ while Cashflow(firm cash flow) Firststock (proportion of the largest shareholder), Ultimatecontrol (ultimate holder), Dual (CEO duality) have no significant relation with Revenue (operating income). But The second dependent variable TobinsQ (Tobin Q value) is significantly correlated with all selected control variables. 


\subsection{Multivariate Regression Analysis}

4.3.1 Government-Enterprise Cooperation and R\&D Input

Table 5. Regression result for government -enterprise cooperation and R\&D input (Rd1)

\begin{tabular}{cccc}
\hline $\mathrm{Rd} 1$ & Coef. & $\mathrm{t}$ & $P>|t|$ \\
\hline $\mathrm{Pt}$ & $-0.00755^{* * *}$ & -4.06 & 0.000 \\
\hline$R O A$ & $0.000959^{* * *}$ & 11.71 & 0.000 \\
\hline Sm & $0.000325^{* * *}$ & 11.83 & 0.000 \\
\hline Size & $-0.00296^{* * *}$ & -4.30 & 0.000 \\
\hline Lev & $0.0192^{* * *}$ & 5.52 & 0.000 \\
\hline Firststock & $-0.0280^{* * *}$ & -8.35 & 0.000 \\
\hline Grow & $8.98 \mathrm{e}-05^{* * *}$ & 8.91 & 0.000 \\
\hline Cons & $16.67^{* * *}$ & 17.84 & 0.000 \\
\hline Industry & & Control & \\
\hline Year & Control \\
\hline$N$ & 6,774 & \\
\hline F-statistics & 164.36 \\
\hline Prob & 0.0000 & \\
\hline Adj- $R^{2}$ & 0.327 \\
\hline
\end{tabular}

Note: * Statistical significance at the $10 \%$ level, ** Statistical significance at the $5 \%$ level

*** Statistical significance at the $1 \%$ level

Table 5 examines the impact of government-enterprise cooperation on corporate R\&D investment. The variable Rd1 (R\&D expenditures/total assets at year-end) representing $R \& D$ investment has a significant negative correlation with whether the government and enterprises cooperate (Pt). The regression coefficient is -0.00755 and is significant at the $1 \%$ level, which verifies the hypothesis 1-b that we proposed before. That is, if other conditions remain unchanged, government-enterprise cooperation has a negative correlation with the investment in $R \& D$ of enterprises.

The regression results also show that the government-enterprise cooperation model cannot promote enterprise technology innovation. It can be seen from the China National Yearbook that the government's investment in science and technology innovation has increased year by year, but the actual regression data shows that the effect is not satisfactory. The government should reformulate new investment policies and expand the scope of enterprises.

In terms of different control variables, the results are like the previous correlation analysis. The regression coefficients of Firststock (proportion of the largest shareholder) is negative and is significant at the level of $10 \%$. Besides, Size (firm size) is negatively correlated with Rd1 (R\&D expenditures/total assets at year-end) and is also significant at the level of $1 \%$. It shows that excessive scale will lead to an increase in internal consumption thus a decrease in investment intensity. 
Table 6. Robustness test for government -enterprise cooperation and R\&D input ( $\mathrm{Rd} 2)$

\begin{tabular}{cccc}
\hline $\mathrm{Rd} 2$ & Coef. & $\mathrm{t}$ & $P>|t|$ \\
\hline $\mathrm{Pt}$ & $-1,461^{* * *}$ & -4.23 & 0.000 \\
\hline ROA & $92.32^{* * *}$ & 6.09 & 0.000 \\
\hline Sm & $16.17 * * *$ & 3.18 & 0.001 \\
\hline Size & $6,113^{* * *}$ & 47.85 & 0.000 \\
\hline Lev & $2,766^{* * *}$ & 4.29 & 0.038 \\
\hline Firststock & $1,295^{* *}$ & 2.08 & 0.006 \\
\hline Grow & $-5.163 * * *$ & -2.76 & 0.030 \\
\hline Cons & $-375,701^{* * *}$ & -2.17 & \\
\hline Industry & & Control & \\
\hline Year & & Control & \\
\hline$N$ & 6,774 & \\
\hline F-statistics & & 198.32 & \\
\hline Prob & & 0.0000 & \\
\hline Adj-R & & 0.370 & \\
\hline
\end{tabular}

Note: * Statistical significance at the $10 \%$ level, ** Statistical significance at the $5 \%$ level, *** Statistical significance at the $1 \%$ level

Table 7. Robustness test for government -enterprise cooperation and R\&D input (Rd3)

\begin{tabular}{cccc}
\hline Rd3 & Coef. & $\mathrm{t}$ & $P>|t|$ \\
\hline $\mathrm{Pt}$ & $-0.194 * * *$ & -2.94 & 0.003 \\
\hline ROA & 0.00319 & 1.10 & 0.273 \\
\hline Sm & $0.00922^{* * *}$ & 9.44 & 0.000 \\
\hline Size & $0.914 * * *$ & 37.31 & 0.000 \\
\hline Lev & 0.196 & 1.59 & 0.000 \\
\hline Firststock & $-0.601 * * *$ & 0.006 \\
\hline Grow & $-0.000990^{* * *}$ & -5.04 & 0.000 \\
\hline Cons & $-163.9 * * *$ & -2.76 & \\
\hline Industry & & -4.93 & \\
\hline Year & Control & \\
\hline$N$ & Control & \\
\hline F-statistics & 6,774 & \\
\hline Prob & 407.63 & \\
\hline Adj- ${ }^{2}$ & Statistical significance at the 1\% level
\end{tabular}

To further verify the reliability of the empirical results, we conduct a robustness test. we use Rd2(R\&D expenditures /10000) and $R d 3=\ln (R \& D$ expenditures +1$)$ to replace $R d 1$ (R\&D expenditures/total assets at year-end) for regression.

From the results of the robustness test in Tables 6 and 7, the two variables representing the R\&D investment, Rd2 and $\mathrm{Rd} 3$, have significant negative relation with whether the government and enterprises cooperate (Pt). The regression coefficients are $-1,461$ and -0.194 respectively and are both significant under the level of $1 \%$, which is consistent with the regression result using variable Rd1. In terms of different control variables, the results are like the previous correlation analysis. Sm (sale margin) is both significantly positively related with $\mathrm{Rd} 2, \operatorname{Rd} 3$ at the level of $1 \%$. 
From the above, the robustness test results are still consistent with the hypothesis 1-b, which further supports the inference of the hypothesis $1-b$ in this paper.

\subsubsection{Government-Enterprise Cooperation and Corporate Performance}

From the results of the multiple regression analysis in Table 8, Revenue (operating income) used to describe corporate performance and government-enterprise cooperation $(\mathrm{Pt})$ show a significant positive correlation, with a regression coefficient of $179,000,000$, which is significant at the level of $1 \%$. It means that the cooperation between government and enterprises has improved the performance of such enterprises and has a positive impact on their operating income. Meanwhile, the R-square of this regression is $40.3 \%$, which indicate that the regression fit is good. The hypothesis 2 -a proposed before is verified. That is, If the other things remain unchanged, government-enterprise cooperation is positively related to corporate performance.

In terms of control variables, we control the year effect (Year) and the industry effect (Industry). They have no positive or negative correlation with the performance of the government-enterprise cooperative corporate, indicating that the company's performance will be affected by the policies, the economic environment and other specific conditions of the year. Size (firm size) and Revenue (operating income) are significant at the level of $1 \%$, indicating that the larger the size of the government-enterprise cooperative firm, the greater the company's operating income. Age (firm life cycle) has no obvious correlation with Revenue (operating income) from the regression coefficient, indicating that the company's survival years has no relevant impact on corporate performance; seniority does not necessarily represent high performance, instead, if new enterprises catch market demand, they can also create high performance. The impact factor of Pay (executive pay) on Revenue (operating income) is 193.0, which is significantly greater than 0 at the $1 \%$ level. It can be judged that the salary level of senior executives in the enterprise has obvious incentive effect on the performance of the company, which confirms the theory of agency theory. To further improve their salary level, corporate executives will pay more attention to the project and business content contributing to corporate performance. On the contrary, because of the uncertainty of technological innovation, high technical requirements, R\&D cycle plants, large investment in research and development, and long investment time, the government-enterprise cooperative enterprises are not enthusiastic about R\&D investment. Firststock (proportion of the largest shareholder) and Revenue (operating income) show a significant positive correlation at the $1 \%$ level, reflecting that when the shareholding ratio of the first largest shareholder is high, the shareholder's supervision of the manager is more effective. Therefore, the interests of the shareholders and the manager are more likely to reach an agreement, which makes the internal development of the enterprise more consistent and more constructive for the improvement of enterprise performance.

Table 8. Regression result for government -enterprise cooperation and performance (Revenue)

\begin{tabular}{cccc}
\hline Revenue & Coef. & $\mathrm{t}$ & $P>|t|$ \\
\hline Pt & $1.790 \mathrm{e}+08^{* * *}$ & 3.48 & 0.000 \\
\hline Size & $8.229 \mathrm{e}+08^{* * *}$ & 41.01 & 0.000 \\
\hline Lev & $1.311 \mathrm{e}+09^{* * *}$ & 14.97 & 0.000 \\
\hline Age & $3.020 \mathrm{e}+06$ & 1.04 & 0.299 \\
\hline Cashflow & $4.859 \mathrm{e}+07$ & 0.56 & 0.575 \\
\hline Pay & $193.0^{* * *}$ & 15.27 & 0.000 \\
\hline Firststock & $8.915 \mathrm{e}+08^{* * *}$ & 9.35 & 0.000 \\
\hline Ultimatecontrol & $-2.254 \mathrm{e}+08^{* * *}$ & -3.49 & 0.000 \\
\hline Dual & $1.770 \mathrm{e}+07$ & 0.77 & 0.443 \\
\hline Cons & $4.38 \mathrm{E}+10$ & 1.63 & 0.103 \\
\hline Industry & & Control \\
\hline Year & Control \\
\hline$N$ & 6,749 \\
\hline F-statistics & 206.04 \\
\hline Prob & 0.0000 \\
\hline Adj- $R^{2}$ & 0.403 \\
\hline
\end{tabular}

Note: * Statistical significance at the $10 \%$ level, $* *$ Statistical significance at the $5 \%$ level, $* * *$ Statistical significance at the $1 \%$ level 
To further verify the reliability of the empirical results, we conduct a robustness test. We use TobinsQ (Tobin Q value), a variable that reflects corporate performance to replace Revenue (operating income) for regression. The regression results are shown in Table 9. TobinsQ (Tobin Q value) and government-enterprise cooperation (Pt) showed a significant positive correlation with a regression coefficient of 0.286 , which is significantly greater than 0 at the $5 \%$ level. This means that the cooperation between government and enterprises has improved the corporate performance of such enterprises and has a positive impact on Tobin's $Q$ value. At the same time, the R-squar value of this regression is $36.1 \%$, which proves that the regression has a good fit. The hypothesis 2-a proposed in this paper is further verified, which shows that the conclusion of this paper has higher stability.

Table 9. Robustness test for government -enterprise cooperation and performance (TobinsQ)

\begin{tabular}{|c|c|c|c|}
\hline TobinsQ & Coef. & $\mathrm{t}$ & $P>|t|$ \\
\hline$P t$ & $0.286^{* *}$ & 2.31 & 0.021 \\
\hline Size & $-1.198 * * *$ & -24.59 & 0.000 \\
\hline Lev & $-1.534 * * *$ & -7.21 & 0.000 \\
\hline Age & -0.0101 & -1.42 & 0.155 \\
\hline Cashflow & $3.249 * * *$ & 15.78 & 0.000 \\
\hline Pay & $1.93 \mathrm{e}-07 * * *$ & 6.23 & 0.000 \\
\hline Firststock & $1.154 * * *$ & 5.01 & 0.000 \\
\hline Ultimatecontrol & $0.943 * * *$ & 6.15 & 0.000 \\
\hline Dual & $0.112 * *$ & 2.00 & 0.045 \\
\hline Cons & $-137.0^{* *}$ & -2.14 & 0.032 \\
\hline Industry & & Control & \\
\hline Year & & Control & \\
\hline$N$ & & 6,394 & \\
\hline$F$-statistics & & 163.45 & \\
\hline Prob & & 0.0000 & \\
\hline$A d j-R^{2}$ & & 0.361 & \\
\hline
\end{tabular}

\section{Conclusions and Suggestions}

This paper takes the government-enterprise cooperation enterprise as the entry point. Through the empirical analysis of the financial data of the GEM listed companies in 2009-2016, under the dual perspectives of technological innovation and corporate performance, we discuss the impact of government-enterprise cooperation on the development and survival of enterprises. The study finds that government-enterprise cooperation has a good side for enterprises. With the cooperation, the company's performance tends to be better. government-enterprise cooperation has a positive effect on corporate performance. However, the cooperation between government and enterprises has inhibited the technological innovation of enterprises to a certain extent. Under the situation that the environment attaches great importance to technological innovation and the amount of government $R \& D$ investment is increasing year by year, compared with nongovernment-enterprise alliances, enterprises that engage in government-enterprise cooperation have invested less in technology innovation and have not achieved substantial and sound development.

Based on the above research conclusions, we propose the following suggestions:

(1) When government and enterprises cooperate, they need to pay attention to the relationship between the government and the market, clarify the cooperation subjectivity of the enterprise, and emphasize the role of market leading. The cooperation between government and enterprises shows their particularity under the special national conditions of our country. The roles of the government and enterprises are not equal. The government is excessively offside, and financial subsidies inhibit innovation and development of enterprises. At the China 19th National Congress of the communist party in 2018, the new government made a core statement on the transformation of China's main contradictions, from "material and cultural needs" to "good life needs." In the direction of "material culture", the government can use the particularity of its role to do all the coordination and guidance. However, at a higher level of demand, the direction pursued by the whole society has changed, the development of economic diversification has become more prominent, and the defects of 
the government's leading role have become increasingly apparent. The government should do a good job in coordinating economic development under a good and stable social environment, such as the cultivation of talents, the establishment of research institutes, etc., to clarify the main position of the company itself in the economic market, and respect the market's survival of the fittest and the Guided renting of supply and demand relations.

(2) The government needs to truly put the government-enterprise cooperation enterprises into the market and compete fairly with other enterprises. To prove that its governance and management are effective, the government will selectively cooperate with enterprises with good industrial resources and good business performance, and better promote local GDP under its guidance. At the same time, government officials have certain promotion criteria for their promotion. To achieve their political goals and social tasks, they cooperate with large-scale and high-quality enterprises to fulfill their political demands (Yuanyuan Gu \& Kunrong Shen,2012). Therefore, the enterprises that cooperate with the government have not been tested by the market and the co This paper takes the government-enterprise cooperation enterprise as the entry point. Through the empirical analysis of the financial data of the GEM listed companies in 2009-2016, under the dual perspectives of technological innovation and corporate performance, we discuss the impact of government-enterprise cooperation on the development and survival of enterprises. The study finds that government-enterprise cooperation has a good side for enterprises. With the cooperation, the company's performance tends to be better. government-enterprise cooperation has a positive effect on corporate performance. However, the cooperation between government and enterprises has inhibited the technological innovation of enterprises to a certain extent. Under the situation that the environment attaches great importance to technological innovation and the amount of government R\&D investment is increasing year by year, compared with non-government-enterprise alliances, enterprises that engage in governmententerprise cooperation have invested less in technology innovation and have not achieved substantial and sound development.

(3) Government-enterprise cooperative enterprises need to reconsider the importance of technological innovation. The positioning of the enterprise itself is very important. Due to the long-term nature of technological innovation, enterprises must adhere to the investment in technological innovation to gain something. The government's fiscal innovation investment ends up as a freely disposable fund of the company (Qiongqiong Zhou \& Hua Qingsong, 2015) but some companies have not used a large amount of government investment only for technological innovation, resulting in a deviation of government-driven enterprises' innovative intentions. Thus, the government should implement segmental distribution, that is, maintain information with enterprises, understand the progress of research and development results, conduct in-depth analysis of the content of innovative projects, make a good decision on the allocation of subsidies, not give enterprises the opportunity to waste subsidies, and focus on the implementation of funds control to eliminate waste and misappropriation.

\section{References}

Bai, C. G., Du, Y. J., Tao, Z. G., \& Tong, Y. T. (2004). Determinants and Trends of Local Protectionism and Industrial Regional Concentration. Economic Research, (4), 29-40.

Chen, W. (2016). Spatial Correlation and Influencing Factors of R\&D Investment of Chinese Enterprises. Economic Management, 38(5), 30-39.

Deng, X. H., \& L, Z. Y. (2014). Group Management, Technology Innovation and Enterprise Performance. Journal of Shanxi University of Finance and Economics, 36(10), 87-97.

Fan, Q., \& H, M. C. (2011). Research on the Impact of Government R\&D Subsidy on National and Regional Independent Innovation Outputs-An Empirical Analysis Based on Panel Data of 28 Provinces in China. Journal of Industrial Engineering and Engineering, (3), 183-188.

Gu, Y. Y., \& Shen, K. R. (2012). Local government behavior and enterprise R\&D investment-An empirical analysis based on Chinese provincial panel data. China Industrial Economy, (10), 77-88.

Guo, J., Chen, Y. Z., \& Liu, W. (2013). The impact of market-policy dual strategic orientation equilibrium on technological innovation performance-Taking high-tech enterprises in Beijing-Tianjin-Hebei region as an example. Journal of Hebei University, 38(4), 135-140.

Li, B., Yue, Y. Q., \& Chen, T. (2016). Export and enterprise independent technological innovation, empirical research from enterprise patent data. World Economy, (12), 72-94.

Li, M. Y., \& Guo, C. Y. (2017). Application of Non-financial Indicators in Enterprise Performance Evaluation System. Finance and Accounting News, (17), 62-65.

Liu, X. Y., \& Lin, W. (2013). The influence of local government behavior on technological innovation of entrepreneurial enterprises-based on the dual perspective of resource allocation and innovation output of technology innovation. 
Research and Development Management, 25(5), 12-25.

Long, J., \& L, H. J. (2012). The influence of the power usage of government agencies on the innovation performance of SMEs-based on the relationship between enterprises and government. Science and Science and Technology Management, 33(5), 96-105.

Luo, M. X., Ma, Q. H., \& Hu, Y. B. (2013). Political Correlation and Enterprise Technology Innovation Performance, Research on the Mediating Role of R\&D Investment. Science Research, 31(6), 938-947.

Sun, D. M., Hu, M. Q., Wang, Z. P., \& Yang, Z. L. (2014). Government Behavior, Financial Development and Regional Innovation Performance-An Empirical Study Based on Provincial Panel Data. Science \& Technology Progress and Policy, 31(20), 34-41.

Xiao, L. P. (2016). Government intervention, industry-university alliance and enterprise technology innovation. Science and Science and Technology Management, 37(03), 21-30.

Xiao, W., \& L, G. B. (2014). Government support, R\&D management and technological innovation efficiency-based on empirical analysis of China's industrial industry. Management World, (4), 71-80.

Yang, R. Y. (2016). Market Competition, Government Behavior and Regional Innovation Performance-An Empirical Study Based on Chinese Provincial Panel Data. Science Research Management, (12),73-81.

Yuan, L. J., \& Z, X. F. (2017). Coupling impact of environmental regulation and government subsidies on technological innovation of enterprises. Resources Science, 39(5), 911-922.

Zhang, R. (2014). Research on Performance Evaluation of Strategic Emerging Industry Enterprises. Accounting Research, (8), 41-44.

Zheng, X. J. (2014). Empirical analysis of the impact of R\&D investment and alliance participation on enterprise innovation capability. Business Age (formerly known as "Business Economic Research"), (33), 101-102.

Zhou, Q. Q., \& Hua, Q. S. (2015). Empirical study on the impact of government and market behavior on the allocation of science and technology resources and technological innovation capabilities. Science and Technology Progress and Countermeasures, 32(15), 14-19.

Zhu, P. F., \& Xu, W. M. (2003). The impact of government's science and technology incentives on R\&D investment and patent output of large and medium-sized industrial enterprises-an empirical study in Shanghai. Economic Research, (6), 45-53.

\section{Copyrights}

Copyright for this article is retained by the author(s), with first publication rights granted to the journal.

This is an open-access article distributed under the terms and conditions of the Creative Commons Attribution license which permits unrestricted use, distribution, and reproduction in any medium, provided the original work is properly cited. 